\title{
RFLP clusters of Mycobacterium tuberculosis strains from the Indian Ocean Region: local and South Asian characteristics
}

\author{
Voahangy Rasolofo Razanamparany ${ }^{1 /+}$, Herimanana H Ramarokoto ${ }^{1}$, Elie J Vololonirina ${ }^{1}$, \\ Tiana Rasolonavalona ${ }^{1}$, Alain Michault ${ }^{2}$, Naidu Pyndiah ${ }^{3}$, Rajbunsing Seenundun ${ }^{3}$, \\ Per Sandven ${ }^{4}$, Suzanne Chanteau ${ }^{1}$
}

${ }^{1}$ Unité des Mycobactéries, Institut Pasteur de Madagascar, BP 1274, 101 Antananarivo, Madagascar ${ }^{2}$ Service Bactériologie Parasitologie Virologie et Hygiène, Groupe Hospitalier Sud Réunion, La Réunion ${ }^{3}$ Ministry of Health and Quality of Life, Mauritius

${ }^{4}$ Division of Infectious Disease Control, Norwegian Institute of Public Health, Oslo, Norway

This is the first study describing the genetic polymorphism of Mycobacterium tuberculosis strains in the Indian Ocean Region. Using IS6110 RFLP analysis, 475 M. tuberculosis isolates from Madagascar, Comoros, Mauritius, Mozambique and La Reunion were compared. Of the 332 IS6110 profiles found, 43 were shared by clusters containing 2-65 strains. Six clusters were common to at least two countries. Of 52 families of strains with similar IS6110 profiles, 10 were common to at least two countries. Interestingly, another characteristic was the frequency (16.8\%) of IS6110 single-copy strains. These strains could be distinguished using the DR marker. This preliminary evaluation suggests genetic similarity between the strains of the Indian Ocean Region. However, additional markers would be useful for epidemiological studies and to assess the ancient transmission of strains between countries of this region.

Key words: Mycobacterium tuberculosis - IS6110 RFLP - Indian Ocean Region

Genetic typing of Mycobacterium tuberculosis complex strains is now commonly used in the molecular epidemiology of tuberculosis (Barnes \& Cave 2003). Since populations have migrated between the different countries in the Indian Ocean Region for many centuries (Ramiandrasoa 1975, Soodyal et al. 1995) it is reasonable to assume that $M$. tuberculosis strains might have travelled between countries as well. To assess if there is a similarity between $M$. tuberculosis strains of the different countries in the Indian Ocean Region, the genetic diversity of strains from Madagascar, Mauritius, La Reunion, Comoros and Mozambique was studied using the standard IS6110 restriction fragment length polymorphism method (IS6110 RFLP) (van Embden et al. 1993).

\section{MATERIALS AND METHODS}

Bacterial isolates - Clinical specimens from 475 new smear positive tuberculosis (SMT + ) patients were studied. There were 319 patients randomly sampled from a previous study in Madagascar (Rasolofo Razanamparany et al. 2001) (about 18 million inhabitants), 17 clinical strains from Comoros (about 600,000 inhabitants), 33 from Mauritius (about 1.2 million inhabitants) and 59 from La Reunion (about 700,000 inhabitants), all isolated

Financial support: French Cooperation (93008), Raoul Follereau Foundation

+ Corresponding author: vrasolof@pasteur.mg

Received 21 September 2008

Accepted 3 March 2009 in 1994-1995, and 47 isolated in Mozambique (about 19 million inhabitants) from 1990-1995. During the study period, the incidence of SMT+ patients was about 60-70 per 100,000 inhabitants in Madagascar and Mozambique and less than 25 per 100,000 in La Reunion, Comoros and Mauritius (WHO 1996).

DNA typing methods - Clinical specimens were decontaminated by the $\mathrm{NaOH}$ - lauryl sulphate method and cultured on standard Lowenstein-Jensen (LJ) medium and on LJ medium supplemented with $0.5 \%$ pyruvate. $M$. tuberculosis isolates were identified by standard biochemical tests (Helali \& Vergez 1993). Genomic DNA was extracted from colonies according to the method described by van Soolingen et al. (1991). DNA fingerprints were obtained using the standardised RFLP method, i.e., Southern blot hybridisation of $P v u I I-$ digested DNA with the IS6110 probe (van Embden et al. 1993). Differentiation of strains having fewer than five copies of IS6110 was done by Southern blot hybridisation of AluI-digested DNA with the DR (direct-repeat) sequence as probe (Hermans et al. 1991). All probes were labelled with horse radish peroxidase and detection was performed with the enhanced chemiluminescence system (Amersham).

Fingerprint patterns were compared using the Taxotron $^{\circledR}$ software (Grimont PAD, Institut Pasteur, Paris). A dendrogram was generated by the unweighted pair group clustering method of averages according to the instructions of the manufacturer (Fig. 1). Matching of profiles was confirmed visually. A cluster was defined as a group of strains with identical RFLP profiles. A family of profiles was defined as a group of profiles with more than 4 IS 6110 copies, differing by less than $1 / 3$ of hybridising bands. 
Size of DNA restriction fragments

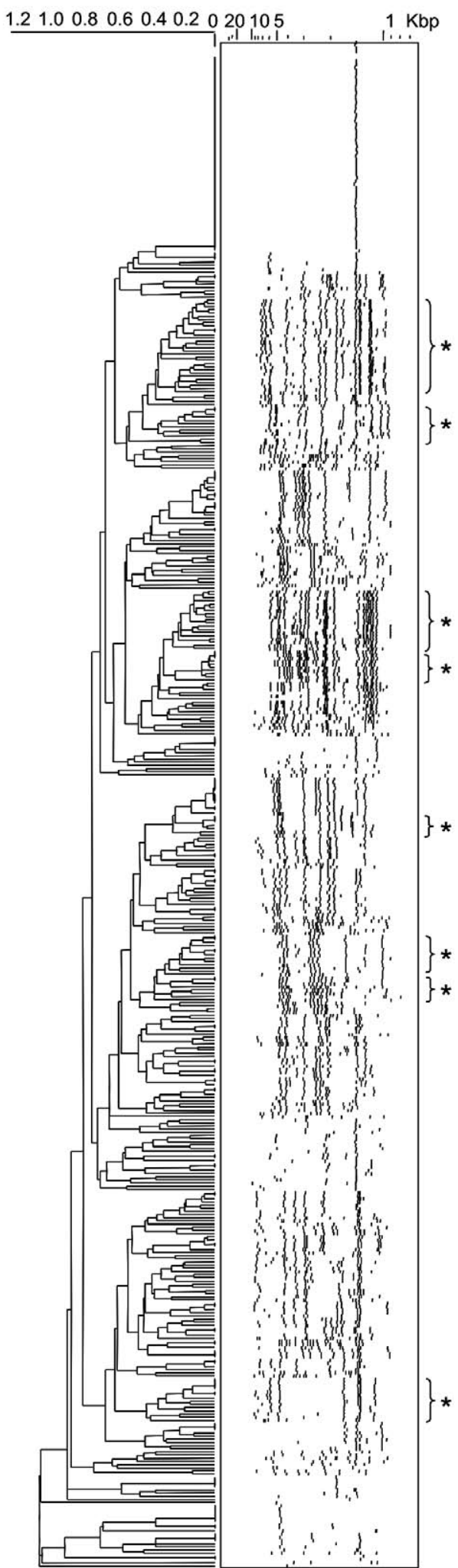

Fig. 1: dendrogram showing the relatedness of IS6110 patterns of 474 Mycobacterium tuberculosis isolates from countries in the Indian Ocean Region. The asterisks indicate the IS6110 patterns families (with more than 5 strains) found in at least two countries. The whole original dendrogram is given as supplementary data.

\section{RESULTS}

Only one strain from Madagascar did not contain the IS6110 element. Among the other $474 \mathrm{M}$. tuberculosis strains, 332 IS6110 profiles were obtained of which 289 were unique and 43 were clusters containing 2-65 strains. Six IS6110 profiles were common to at least two countries.

The 474 strains had IS6110 copy numbers ranging from one-26 (Fig. 2). Strains with only one IS6110 copy were frequent $(16.8 \%)$ in the Indian Ocean Region. This frequency, however, varied between countries: Madagascar: 21.3\%, Mozambique: $13.3 \%$, La Reunion: $6.2 \%$, Mauritius: $6 \%$ and Comoros: $0 \%$. Seven different sizes of the IS6110-hybridising fragment were observed among the one-copy strains: $1.35 \mathrm{~kb}$ (2 strains), $1.45 \mathrm{~kb}$ (65 strains), $1.56 \mathrm{~kb}$ (1 strain), $1.8 \mathrm{~kb}$ (4 strains identified as Mycobacterium bovis), $4.1 \mathrm{~kb}$ (1 strain), $4.8 \mathrm{~kb}$ (6 strains) and $5.1 \mathrm{~kb}(1 \mathrm{strain})$. The more frequent pattern with the $1.45 \mathrm{~kb}$ hybridising band was found in all countries and the $1.35 \mathrm{~kb}$ fragment profile was found only in Madagascar and La Reunion. The five other one-IS6110 copy patterns were observed only in Madagascar.

One hundred and thirty-one isolates had less than five copies of IS6110. These isolates could be differentiated using DR RFLP analysis. Among 123 strains typed with this method, 64 different DR profiles were found (data not shown). Fifty two strains had a unique DR profile and 71 were classified into 12 clusters of two-19 strains. But no identical DR pattern was found in two different countries.

The 344 strains having more than 4 IS6110 copies were classified by pooling those with similar IS6110 patterns (i.e., patterns sharing more than $2 / 3$ identical hybridising bands) into families. Using this scheme, 97 strains had unique patterns and 197 were classified into 52 families of two-30 strains. Ten of the families were found in at least two countries.

\section{DISCUSSION}

In a previous study in Madagascar, RFLP with the IS6110 marker revealed a high proportion of IS6110 single-copy strains (Rasolofo Razanamparany et al. 2001). One characteristic of the Indian Ocean Region countries, excepting Comoros, was the relatively high frequency of these IS6110 single-copy strains. Such strains have been widely described in Southern Asiatic Regions (Das et al. 2005). Their presence in the Indian Ocean Region could be explained by the number of Asian migrants there. The most frequent profile was that with a $1.45 \mathrm{~kb}$ IS6110 band, one of the most common patterns worldwide. The DR RFLP patterns of those isolates varied from one country to another, suggesting that although they derived from a common ancestor, they have since evolved further separately. Upon classifying the different IS6110 patterns into families of similar patterns, 10 families were found to be common to at least two countries. This indicates that genetic similarity may exist between the strains in the different countries of the Indian Ocean Region.

Even though RFLP analysis is the gold standard of M. tuberculosis genotyping, using only the IS6110 

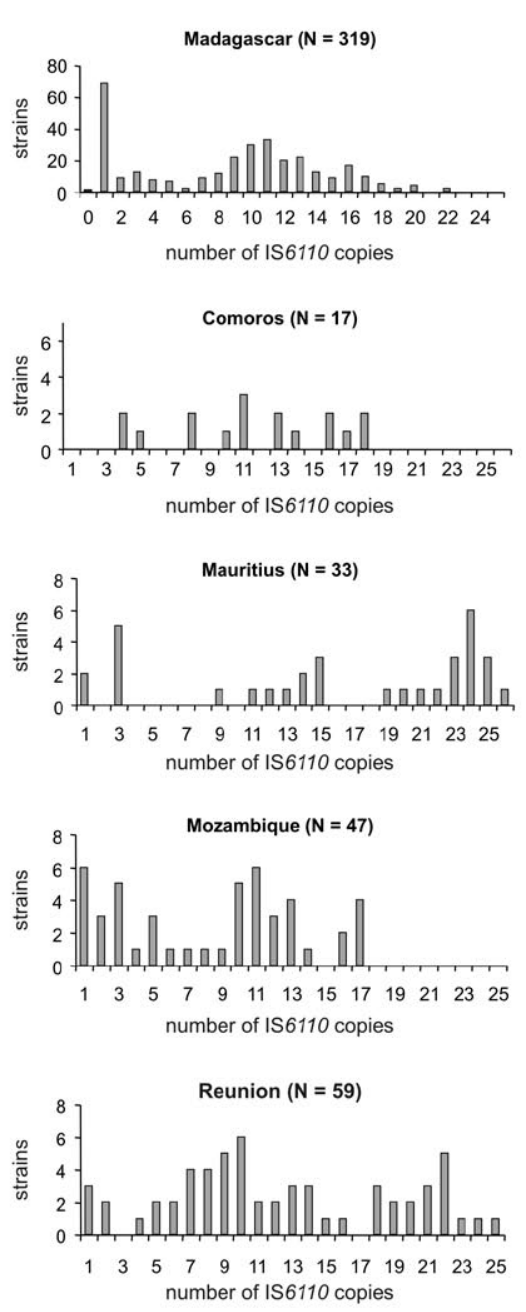

Fig. 2: number of IS6110 copies in 475 Mycobacterium tuberculosis isolates from the Indian Ocean Region.

RFLP and DR RFLP's limits one's ability to compare Indian Ocean genotypes with genotypes from other regions of the world. A previous study by spoligotyping showed that Malagasy strains were close to ancient Asiatic strains, suggesting that they may have migrated with populations (Ferdinand et al. 2005, Hurles et al. 2005). So spoligotyping of more strains from the other Indian Ocean countries, or other methods like the MIRUS/VNTR typing (Barnes \& Cave 2003, Kremer et al. 2005) or single-nucleotide polymorphism-tagging (Filliol et al. 2006) could be useful to assess ancient transmission of strains between the countries of this region and to compare them with strains from other countries of the world.

\section{ACKNOWLEDGEMENTS}

To Dr. JT Jeque (National Tuberculosis Reference Laboratory, Maputo, Mozambique), Dr. P. Feyaerts (Hôpital El Maarouf, Moroni, RFI des Comores) and Dr. R. Josse (HIA Robert Picqué, Bordeaux, France), for their collaboration.

\section{REFERENCES}

Barnes PF, Cave MD 2003. Molecular epidemiology of tuberculosis. N Engl J Med 349: 1149-1156.

Das SD, Narayanan S, Hari L, Hoti SL, Thangathurai RK, Charles N, Jaggarajamma K, Narayanan, PR 2005. Differentiation of highly prevalent IS6110 single-copy strains of Mycobacterium tuberculosis from a rural community in South India with an ongoing DOTS programme. Infect Genet Evol 5: 67-77.

Ferdinand S, Sola, C, Chanteau S, Ramarokoto H, Rasolonavalona T, Rasolofo-Razanamparany V, Rastogi N 2005. A study of spoligotyping-defined Mycobacterium tuberculosis clades in relation to the origin of peopling and the demographic history in Madagascar. Infect Genet Evol 5: 340-348.

Filliol I, Motiwala AS, Cavatore M, Qi W, Hazbon MH, Bobadilla del Valle M, Fyfe J, Garcia-Garcia L, Rastogi N, Sola C, Zozio T, Guerrero MI, Leon CI, Crabtree J, Angiuoli S, Eisenach KD, Durmaz R, Joloba ML, Rendon A, Sifuentes-Osornio J, Ponce de Leon A, Cave MD, Fleischmann R, Whittam TS, Alland D 2006. Global phylogeny of Mycobacterium tuberculosis based on single nucleotide polymorphism (SNP) analysis: insights into tuberculosis evolution, phylogenetic accuracy of other DNA fingerprinting systems, and recommendations for a minimal standard SNP set. J Bacteriol 18: 759-772.

Helali NE, Vergez P 1993. Identification des mycobactéries. Feuill Biol 190: 5-18.

Hermans PWM, van Soolingen D, Bilk EM, de Haas PEW, Dale JW, van Embden JAD 1991. Insertion element IS687 from Mycobacterium bovis is located in a hot-spot integration region for insertion elements in Mycobacterium tuberculosis complex strains. Infect Immun 59: 2695-2705.

Hurles ME, Sykes BC, Jobling MA, Forster P 2005. The dual origin of the Malagasy in Island Southeast Asia and East Africa: evidence from maternal and paternal lineages. Am J Hum Genet 76: 894-901.

Kremer K, Arnold C, Cataldi A, Gutierrez MC, Haas WH, Panaiotov S, Skuce RA, Supply P, van der Zanden AGM, van Soolingen D 2005. Discriminatory power and reproducibility of novel DNA typing methods for Mycobacterium tuberculosis complex strains. J Clin Microbiol 43: 5628-5638.

Ramiandrasoa F 1975. Atlas historique du peuplement de Madagascar, Université de Madagascar (EESDEGS), Antananarivo, 31 pp.

Rasolofo Razanamparany V, Ramarokoto, H, Aurégan G, Gicquel $\mathrm{B}$, Chanteau S 2001. A combination of two genetic markers is sufficient for RFLP typing of Mycobacterium tuberculosis in areas with a high incidence of tuberculosis. J Clin Microbiol 39: 1530-1535.

Soodyal H, Jenkins T, Stoneking M 1995. Polynesian mtDNA in the Malagasy. Nat Genet 10: 377-378.

van Embden JDA, Cave MD, Crawford JT, Dale JW, Eisenach KD, Gicquel B, Hermans PWM, Martin C, McAdam R, Shinnick TM, Small P 1993. Strain identification of Mycobacterium tuberculosis by DNA fingerprinting: recommendations for a standardized methodology. J Clin Microbiol 31: 406-409.

van Soolingen D, Hermans PWM, de Haas PEW, Soll DR, van Embden JDA 1991. Occurrence and stability of insertion sequences in Mycobacterium tuberculosis complex strains: evaluation of an insertion sequence dependant DNA polymorphism as a tool in the epidemiology of tuberculosis. J Clin Microbiol 29: 2578-2586.

WHO - World Health Organization 1996. Tuberculosis notification update. Wkly Epidemiol Rec 71: 65-72. 